\title{
Performance of bone mineral density and trabecular bone score in assessment of bone quality in Egyptian male patients with ankylosing spondylitis
}

\author{
Yasmin Adel ${ }^{1}$, Mohamed Ali El Adalany ${ }^{2}$ and Sherine Abdel Rahman Abdel Karim Bassiouni ${ }^{{ }^{*}}$ (1)
}

\begin{abstract}
Background: Osteoporosis is a common complication of ankylosing spondylitis (AS) even in the early stages of disease; however, previously published studies have demonstrated large discrepancies in the reported incidence of osteoporosis, based on measurement of bone mineral density (BMD). The aim of the present study was to compare bone quality using trabecular bone score (TBS) between AS patients and healthy controls and to evaluate factors associated with TBS in patients with AS.

Results: Ankylosing spondylitis patients had significantly lower BMD and T score at the neck of femur and lower total hip BMD than controls (BMD $p=0.010$ and 0.032 respectively), (T score $p=0.006$ and $p=0.025$ respectively). The mean TBS was significantly lower in AS patients than in controls $(p<0.001)$. Lumbar spine TBS was directly correlated with BMI $(p=0.029)$ and BMD at the neck of femur $(p=0.016)$ and BMD of total hip $(p=0.007)$ while inversely correlated with the Bath AS Metrology Index (BASMI) $(p=0.026)$, the modified Stoke AS Spinal Score (mSASS) $(p=0.029)$, ESR $(p=0.031)$, and CRP $(p=0.033)$.

Conclusion: TBS evaluation detected lower bone quality in the lumbar spine in patients with AS when compared with matched controls, while lumbar BMD failed to identify it. These findings encourage the use of TBS as a beneficial tool to recognize the risk of axial osteoporosis as early as possible in AS patients. Also, we recommend its use for regular follow up of drug treatment for those patients.
\end{abstract}

Keywords: Ankylosing spondylitis, Osteoporosis, Dual energy X-ray absorptiometry, Trabecular bone score

\section{Background}

Ankylosing spondylitis (AS) is a chronic immunemediated inflammatory disease primarily involving the sacroiliac joints and the axial skeleton. Estimates indicate that prevalence of AS is approximately $0.2-0.5 \%$ in general population. Usually, AS is diagnosed in people under the age of 40, and occurs more often in men than women in a 2:1 ratio [1].

\footnotetext{
* Correspondence: sherineabdelrahman@yahoo.com

${ }^{1}$ Physical Medicine, Rheumatology and Rehabilitation Department, Faculty of Medicine, Mansoura University, Mansoura, Egypt

Full list of author information is available at the end of the article
}

Ankylosing spondylitis is a remodeling arthritis characterized by a very obvious paradox of bone formation and loss taking place at sites in close proximity [2]. Osteoporosis is a coherent characteristic of inflammatory diseases. It is a common complication of AS even in the early stages of illness [3]. Yet, AS is also marked by new growth of bone leading to the development of syndesmophytes and subsequent vertebral ankylosis [4]. Accordingly, previously published studies have displayed significant differences in the recorded incidence of osteoporosis, based on bone mineral density (BMD) measurements in patients with AS ranging from 18.7 [5] to $62 \%[6]$. 
Dual x-ray absorptiometry (DXA) has limited accuracy for measuring of BMD in AS patients due to the unreliability of spinal measurements, particularly in advanced disease with syndesmophyte presence and hyperossification [7]. DXA is also hard to be analyzed due to ligamentous calcifications overlying the vertebrae, and sclerosis affecting the vertebral endplates, both leading to erroneously increased readings for spinal $\operatorname{BMD}[8,9]$. A further restriction of BMD based on DXA being a bidimensional analysis that is not capable of differentiating between the trabecular and cortical bone compartments, whereas inflammatory diseases ordinarily cause entirely diverse levels of degradation in both compartments $[10,11]$.

Measurement of trabecular bone score (TBS) is an innovative measure to assess bone microarchitecture. It is a textural index, which estimates the variance in the grey-level pixel in DXA illustration of the lumbar spine, that way, provides a circuitous index of trabecular bone microarchitecture [12]. Previous studies showed that spinal osteophytes do not affect the TBS, despite that presence of osteophytes results in overrating of BMD in patients with lumbar spondylosis [13, 14]. This observation proposes that TBS can evaluate the bone microarchitecture in patients with AS inspite the presence of syndesmophytes.

To our knowledge, scanty studies had evaluated the utility of TBS in diagnosis of osteoporosis in patients with AS in comparison to matched controls. The objective of this study was therefore to compare the quality of bone between AS patients and healthy controls using TBS and to assess TBS-related factors in AS patients.

\section{Methods}

\section{Patients and controls}

In this study, a total of 40 consecutive male AS patients were invited to take part. Patients were recruited from the Rheumatology and Rehabilitation outpatient clinic, between January 2019 and January 2020. Ankylosing spondylitis was diagnosed according to The Assessment of SpondyloArthritis international Society (ASAS) criteria for axial spondyloarthritis (axSpA) [15]. During the same period, 40 age-matched healthy males were invited to participate in the study as a control group.

Patients or controls with thyroid or parathyroid diseases, renal or liver disease were excluded from the study. Those taking any drug that may possibly interpose with bone metabolism including bisphosphonates, teriparatide, anticonvulsants, anticoagulants, calcium, and corticosteroids also were excluded. None of the participants was using vitamin D supplements.

Prior to enrollment and data collection, the study's aim and procedures were explained to all participants who provided informed written consent. The research was approved by the Institutional Review Board (IRB) (R/20.05.839).

\section{Personal and clinical data}

Personal data including age, current smoking status, alcohol intake, and history of previous or current medications used were obtained from all participants through history taking and checking of patients' medical records. Duration of symptoms was also recorded for the patients. The medications used to treat AS have been collected from medical records, including intake of nonsteroidal anti-inflammatory drugs (NSAIDs), diseasemodifying anti-rheumatic drugs (DMARDs), and biological therapy. Body mass index (BMI) was calculated for all participants.

\section{Ankylosing spondylitis-specific indices}

The activity of AS disease was evaluated using the AS disease activity score (ASDAS) [16] and Bath AS Disease Activity Index (BASDAI) [17]. In the ASDAS score, back pain, patient global assessment, duration of morning stiffness, and peripheral pain/swelling were all assessed on a numerical rating scale (from 0 to 10). The 3 cutoffs selected to separate the activity states were $<1.3$

Table 1 Clinical features, current medication, composite indices, and laboratory findings of the AS patients

\begin{tabular}{lll}
\hline & Range & Mean \pm SD \\
\hline Disease duration (years) & $4-29$ & $17.1 \pm 7.2$ \\
Peripheral involvement N (\%) & $15(37.5 \%)$ & \\
Current medications & & \\
NSAIDs N (\%) & $31(77.5 \%)$ & \\
Methotrexate N (\%) & $4(10.0 \%)$ & \\
Sulfasalazine N (\%) & $28(70.0 \%)$ & \\
TNF inhibitor N (\%) & $23(57.5 \%)$ & \\
Composite indices & & $2.90 \pm 1.2$ \\
ASDAS-CRP & $1.20-4.60$ & $2.63 \pm 0.92$ \\
ASDAS-ESR & $1.10-4.02$ & $3.89 \pm 1.14$ \\
BASDAl & $1.70-5.70$ & $3.83 \pm 1.37$ \\
BASFI & $1.30-5.90$ & $3.74 \pm 1.41$ \\
BASMl & $1.60-5.90$ & $9.00 \pm 4.08$ \\
ASQol & $3-15$ & $14.90 \pm 6.92$ \\
mSASSS & $2-27$ & $30.9 \pm 11.0$ \\
Laboratory findings & & $14.1 \pm 6.9$ \\
ESR (mm) & $15-53$ & \\
CRP (mg/dl) & $3.7-27.2$ & \\
\hline
\end{tabular}

NSAIDs non-steroidal anti-inflammatory drugs, TNF tumor necrosis factor, ASDA S-CRP Ankylosing Spondylitis Disease Activity Score- C-reactive protein, ASDASESR Ankylosing Spondylitis Disease Activity Score-erythrocyte sedimentation rate, BASDAl Bath Ankylosing Spondylitis Disease Activity Index, BASFI Bath Ankylosing Spondylitis Function Index, BASMI Bath Ankylosing Spondylitis Metrology Index, ASQoL Ankylosing Spondylitis Quality of Life, mSASS modified Stoke Ankylosing Spondylitis Spinal Score 
between "inactive disease" and "moderate disease activity," < 2.1 between "moderate disease activity" and "high disease activity," and $>3.5$ between "high disease activity" and "very high disease activity." The BASDAI consists of a 1 through 10 scale (one being no problem and 10 being the worst problem) which is used to answer 6 questions pertaining to the 5 major symptoms of AS: fatigue, spinal pain, joint pain/swelling, areas of localized tenderness (enthesitis), morning stiffness duration, and morning stiffness severity. The mean of the two scores relating to morning stiffness was taken. The resulting 0 to 50 score was divided by 5 to give a final $0-10$ BASDAI score. Scores of 4 or greater suggest suboptimal control of disease.

Bath AS Metrology Index (BASMI) was used to measure the spinal mobility [18]. Five simple clinical measurements were included in the index: tragus to wall distance, lumbar side flexion, modified Schober's, cervical rotation, and intermalleolar distance. For cervical rotation, lumbar side flexion and tragus to wall, a mean of the left and right measurements were taken. The higher the BASMI score, the more severe the patient's limitation of movement due to their AS.

Functional status of patients was evaluated using the Bath AS Functional Index (BASFI), which is a set of 10 questions. The scores of all questions were added and divided by 10 . The higher the BASFI score, the more severe the patient's limitation of function due to their AS [19].

The quality of life of patients was assessed using AS Quality of Life questionnaire (ASQoL). It consists of 18 items requesting a "yes" or "no" response to questions related to the impact of the disease (including pain) on sleep, mood, motivation, ability to cope, activities of daily living, independence, relationships, and social life. A score of one was given to a response of "yes" on each item, and all item scores were summed to a total score

Table 2 Comparison of DXA findings between AS patients and controls

\begin{tabular}{llll}
\hline & AS patients group & Controls group & $p$ \\
\hline BMD $\left(\mathrm{g} / \mathrm{cm}^{2}\right)$ & & & \\
Lumbar spine & $0.997 \pm 0.087$ & $1.017 \pm 0.104$ & 0.338 \\
Neck of femur & $0.867 \pm 0.184$ & $0.962 \pm 0.135$ & 0.010 \\
Total hip & $0.898 \pm 0.099$ & $0.943 \pm 0.084$ & 0.032 \\
Distal radius & $0.822 \pm 0.229$ & $0.860 \pm 0.254$ & 0.486 \\
T score & & & \\
Lumbar spine & $-2.31 \pm 0.68$ & $-2.41 \pm 0.75$ & 0.535 \\
Neck of femur & $-2.58 \pm 0.54$ & $-2.21 \pm 0.62$ & 0.006 \\
Total hip & $-2.57 \pm 0.52$ & $-2.58 \pm 0.62$ & 0.025 \\
Distal radius & $-2.44 \pm 0.44$ & $-2.34 \pm 0.50$ & 0.362 \\
\hline AS ankylosing spondylitis, BMD bone mineral density, DXA Dual & \\
X-ray absorptiometry & & &
\end{tabular}

with a range of 0 to 18 . Higher scores indicate worse health related quality of life [20].

\section{Laboratory investigations}

The serum levels of C-reactive protein (CRP) and erythrocyte sedimentation rate (ESR) were estimated as indicators of inflammation in all patients on the same data collection day.

\section{Radiological assessments}

The structural damage in the cervical and lumbar spine was scored by the modified Stoke AS Spinal Score (mSASSS) resulting in a final summation score ranging from null to 72 [21].

\section{DEXA scan}

DXA was used to measure BMD and T score (Lunar Prodigy densitometer, GE Healthcare, Madison, WI, USA). Skillful operators took all measurements using the same machine and standardized participant positioning strategies. BMD and T score were calculated in the lumbar spine (L1-L4), the left hip (femoral neck and total proximal femur), and distal radius.

\section{Analyzing lumbar spine TBS}

TBS was analyzed using DXA images precisely taken for the same part examined for lumbar BMD measurements (L1-L4). Using TBS iNight software version 2.1 (Med-I maps, Merignac, France), lumbar spine DXA images were reanalyzed. Patients were divided into 3 TBS groups according to guidelines for fracture risk [22]: any TBS $\geq 1.31$ was deemed as normal; TBS values between 1.23 and 1.31 were consistent as partially degraded structure; and any TBS $\leq 1.23$ was considered as degraded structure.

\section{Statistical analysis}

All statistical analyses were performed using SPSS for windows version 20.0 (SPSS, Chicago, IL). All continuous data were normally distributed and were expressed in mean \pm standard deviation (SD). Categorical data was expressed in terms of number and percentage. The comparisons were made using independent sample Student's $t$ test for variables with continuous data. The chi-square test was used to compare variables with categorical results. The correlation coefficient test used to evaluate the correlations between continuous variables. Statistical significance was established at $p \leq 0.05$.

\section{Results}

The study included 40 AS male patients with an average age of $44.7 \pm 12.2$ years (ranging from 22 to 64 years) and 40 healthy males served as a control group with an average age of $45.6 \pm 12.0$ years (ranging from 24 to 64 
Table 3 Comparison of TBS between AS patients and controls

\begin{tabular}{llll}
\hline & AS patients group & Controls group & $p$ \\
\hline TBS lumbar spine & $1.22 \pm 0.12$ & $1.35 \pm 0.19$ \\
TBS status N (\%) & & & \\
$\quad$ Normal bone architecture & $5(12.5 \%)$ & $18(45.0 \%)$ \\
$\quad$ Partially degraded bone architecture & $16(40.0 \%)$ & $12(30.0 \%)$ \\
$\quad$ Degraded bone architecture & $19(47.5 \%)$ & $10(25.0 \%)$ & 0.001 \\
\hline AS anky
\end{tabular}

years). The AS patients and the controls had an average BMI of $26.7 \pm 4.2 \mathrm{~kg} / \mathrm{m}^{2}$ (ranging from 20.6 to $33.7 \mathrm{~kg} /$ $\mathrm{m}^{2}$ ) and $25.6 \pm 3.9 \mathrm{~kg} / \mathrm{m}^{2}$ (ranging from 20.0 to $32.8 \mathrm{~kg} /$ $\mathrm{m}^{2}$ ) respectively. Nine (22.5\%) AS patients and 13 (32.5\%) controls were current smokers. All patients with AS had axial affection, while only 15 patients $(37.5 \%)$ had peripheral involvement. There was no significant difference in age, BMI, and current smoking status between the AS patients and controls.

The clinical findings, current medication intake, the composite indices (for measurement of disease activity, spinal mobility, functional index, quality of life and radiological structural damage) as well as the laboratory results of the AS patients are demonstrated in Table 1.

DXA examination revealed that the BMD and T scores at lumbar spine and distal radius did not vary significantly between AS patients and controls. On the other hand, AS patients had significantly lower BMD at the neck of femur and lower total hip BMD than controls $(p$ $=0.010$ and 0.032), respectively. In addition, AS patients had also significantly lower $\mathrm{T}$ score of neck of femur and total hip $\mathrm{T}$ scores compared to controls $(p=0.006$ and $p=0.025$ respectively) (Table 2 ).

The mean TBS in patients with AS was significantly lower than in controls $(1.22 \pm 0.12$ vs. $1.35 \pm 0.19$ respectively: $95 \% \mathrm{CI},-0.201 ;-0.059, p<0.001$ ) (Table 3 ). The rate of presence of degraded bone microarchitecture in all participants in the current study was determined according to the TBS measurements. In the AS group, $12.5 \%$ of patients had a normal TBS value, $40.0 \%$ had partially degraded bone microarchitecture, while $47.5 \%$ had degraded bone microarchitecture. In the control group, $45.0 \%$ subjects had normal TBS value, $30.0 \%$ had partially degraded bone microarchitecture, while only $25.0 \%$ of controls had degraded bone microarchitecture. All the differences between AS and control groups were significant $(p=0.005)$ (Table 3).

Figure 1 shows a single patient record of DEXA scan that shows the decreased BMD at hip with normal axial bone mass and the same patient's TBS denoting degraded bone microarchitecture.

Lumbar spine TBS was directly correlated with BMI ( $p$ $=0.029)$ and BMD at the femur neck $(p=0.016)$ and total hip $\operatorname{BMD}(p=0.007)$, while correlated inversely with the BASMI $(p=0.026)$, mSASS $(p=0.029), \operatorname{ESR}(p$ $=0.031)$, and CRP $(p=0.033)$ (Table 4$)$. On the other hand, lumbar spine TBS in AS patients did not show significant association with smoking, peripheral joint involvement nor current medication intake (Table 5).

\section{Discussion}

The major findings of the current study were (a) ankylosing spondylitis patients had significantly lower TBS than controls meanwhile lumbar spine BMD did not show significant difference between AS patients and controls; (b) ankylosing spondylitis patients' TBS were directly correlated with BMI and BMD of the femur neck and total hip, while inversely correlated with the BASMI, mSASS, ESR, and CRP.

DXA technique represents the gold standard for evaluating BMD that is currently considered the best predictor of osteoporotic fractures; however, DXA is constrained by the bidimensional nature of the radiographic projection [23]. In diseases like AS and osteoarthritis, formation of syndesmophytes or osteophytes in the lumbar spine, or sclerosis of the vertebral endplates, leads to inadequate DXA results. In such conditions, DXA commonly overestimate BMD values, resulting in overlooked inflammation-related bone loss [1, 24].

In agreement with our results, average lumbar spine and distal radius BMD have been reported to be comparable in AS patients and in controls; meanwhile, the average neck of femur and total hip BMD were significantly lower in AS patients compared to controls [11, 25]. That is why we targeted the axial skeleton to measure the TBS of the lumbar spine rather than the femoral neck since the major pathology of syndysmophytes and calcifications occurs axially which gave a false increase in BMD at the lumbar spine and obscured the lumbar osteoporosis.

In addition, Caparbo et al. found that TBS was significantly lower in AS patients than healthy controls. The same study also found that $41 \%$ of AS patients had TBS below the normal cut-off point (i.e., below 1.31) in comparison to just $7.7 \%$ of healthy controls. Furthermore, $21.9 \%$ of AS patients reported TBS with degraded bone structure compared to none of the controls [25]. In another study, Kang et al. found no difference between 

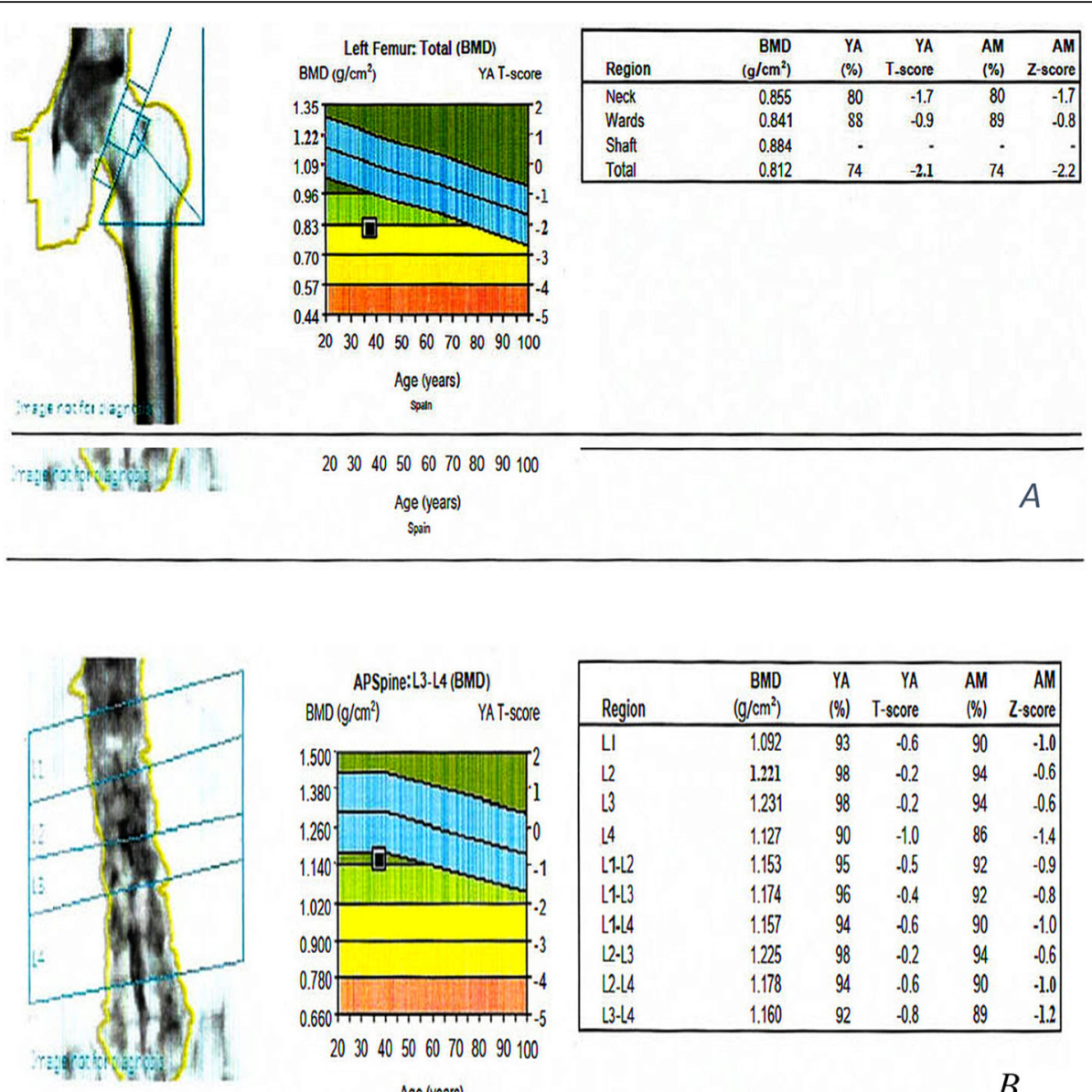

\begin{tabular}{|c|c|c|c|c|c|}
\hline Region & $\begin{array}{r}\text { BMD } \\
\left(\mathrm{g} / \mathrm{cm}^{2}\right)\end{array}$ & $\begin{array}{l}Y_{A} \\
(\%)\end{array}$ & $\begin{array}{r}Y A \\
T \text {-score }\end{array}$ & $\begin{array}{l}\text { AM } \\
(\%)\end{array}$ & $\begin{array}{l}\text { AM } \\
\text { Z-score }\end{array}$ \\
\hline LI & 1.092 & 93 & -0.6 & 90 & -1.0 \\
\hline L2 & 1.221 & 98 & -0.2 & 94 & .0 .6 \\
\hline เ3 & 1.231 & 98 & -0.2 & 94 & -0.6 \\
\hline$\lfloor 4$ & 1.127 & 90 & -1.0 & 86 & -1.4 \\
\hline L1-L2 & 1.153 & 95 & .0 .5 & 92 & -0.9 \\
\hline L1-L3 & 1.174 & 96 & .0 .4 & 92 & -0.8 \\
\hline L1.L4 & 1.157 & 94 & -0.6 & 90 & -1.0 \\
\hline L2-13 & 1.225 & 98 & -0.2 & 94 & -0.6 \\
\hline L2.14 & 1.178 & 94 & .0 .6 & 90 & -1.0 \\
\hline เ3-L4 & 1.160 & 92 & -0.8 & 89 & -1.2 \\
\hline
\end{tabular}

Age (years)

\section{B}

Span

SPINE TBS REPORT

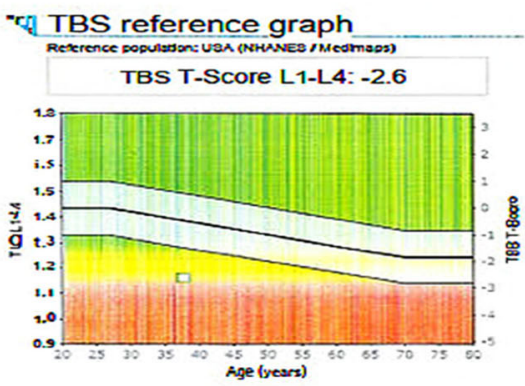

惯 TBS Mapping

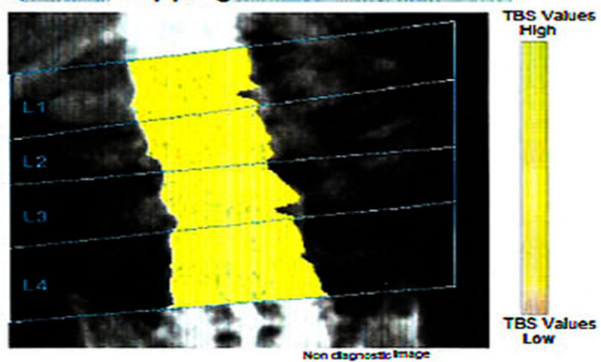

घํㅐ FRAX

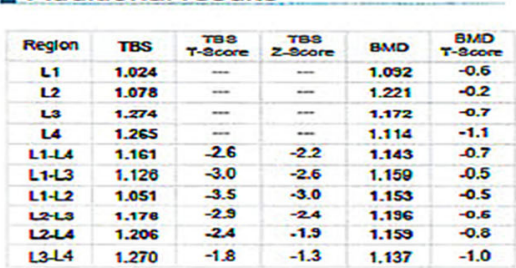

Comments

Fig. 1 A single patient record of DEXA scan. a The decreased BMD at hip. $\mathbf{b}$ Normal axial bone mass. $\mathbf{c}$ TBS of the same patient denoting degraded bone microarchitecture 
Table 4 Correlation of TBS with age, BMI, clinical features, composite indices, and laboratory findings of ankylosing spondylitis patients

\begin{tabular}{|c|c|c|}
\hline & $r$ & $p$ \\
\hline Age & 0.276 & 0.084 \\
\hline BMI & 0.346 & $0.029^{*}$ \\
\hline Duration of disease & 0.285 & 0.075 \\
\hline ASDAS-CRP & -0.215 & 0.183 \\
\hline ASDAS-SER & -0.184 & 0.255 \\
\hline BASDAI & -0.166 & 0.305 \\
\hline BASFI & -0.222 & 0.169 \\
\hline BASMI & -0.352 & $0.026^{*}$ \\
\hline ASQoL & -0.122 & 0.454 \\
\hline mSASS & -0.345 & $0.029^{*}$ \\
\hline ESR & -0.342 & $0.031^{*}$ \\
\hline CRP & -0.338 & $0.033^{*}$ \\
\hline BMD at lumbar spine & 0.242 & 0.132 \\
\hline BMD at femoral neck & 0.378 & $0.016^{*}$ \\
\hline BMD at total hip & 0.423 & $0.007^{*}$ \\
\hline BMD at wrist & 0.285 & 0.074 \\
\hline \multicolumn{3}{|c|}{$\begin{array}{l}\text { ASDAS Ankylosing Spondylitis Disease Activity Score, ASQoL Ankylosing } \\
\text { Spondylitis Quality of Life, BASDAI Bath Ankylosing Spondylitis Disease Activity } \\
\text { Index, BASFI Bath Ankylosing Spondylitis Function Index, BASMI Bath } \\
\text { Ankylosing Spondylitis Metrology Index, BMD bone mineral density, BMI body } \\
\text { mass index, CRP C-reactive protein, ESR erythrocyte sedimentation rate, mSASS } \\
\text { modified Stoke Ankylosing Spondylitis Spinal Score, TBS trabecular bone score, } \\
\text { TNF tumor necrosis factor }\end{array}$} \\
\hline
\end{tabular}

BMD in the lumbar spine of patients with axSpA and that of matched controls inspite of the presence of differences in bone microarchitecture evaluated through TBS [26].

Paolino et al. also assessed bone micro-architectural status of the lumbar spine in patients with AS. Their results showed that AS patients had increased BMD and decreased TBS measures. The study concluded that the TBS can provide skeletal microarchitecture degradation that is not captured from BMD measurement [27].

These findings indicate that lumbar TBS spotted bone degradation in the lumbar spine of AS patients more precisely than lumbar BMD, denoting that the TBS is a more valuable tool to evaluate vertebral bone deterioration in AS patients. Apparently, the presence of syndesmophytes in the lumbar spine do not affect the TBS results and warrants more accurate analysis of vertebral trabecular bone [24]. The significantly lower TBS in the AS patients in comparison to healthy controls reveals the decreased strength of bone associated with a motley and more porous trabecular bone [22].

Inflammation seems to have diverse impacts on trabecular and cortical bone compartments. The inflammatory process which is the hallmark of AS mostly affects the trabecular bone $[10,28]$. In support to this finding,
Table 5 Comparison of the TBS in patients with and without smoking, peripheral joint involvement and drug intake in AS patients

\begin{tabular}{|c|c|c|}
\hline & TBS $($ mean \pm SD) & $p$ \\
\hline \multicolumn{3}{|c|}{ Smoking } \\
\hline Yes & $1.25 \pm 0.12$ & \multirow[t]{2}{*}{0.362} \\
\hline No & $1.21 \pm 0.11$ & \\
\hline \multicolumn{3}{|c|}{ Peripheral joint involvement } \\
\hline Yes & $1.24 \pm 0.12$ & \multirow[t]{2}{*}{0.412} \\
\hline No & $1.21 \pm 0.11$ & \\
\hline \multicolumn{3}{|c|}{ Medication intake } \\
\hline \multicolumn{3}{|c|}{ - NSAIDs } \\
\hline Yes & $1.22 \pm 0.12$ & \multirow[t]{2}{*}{0.608} \\
\hline No & $1.20 \pm 0.10$ & \\
\hline \multicolumn{3}{|c|}{ - Methotrexate } \\
\hline Yes & $1.27 \pm 0.03$ & \multirow[t]{2}{*}{0.348} \\
\hline No & $1.21 \pm 0.12$ & \\
\hline \multicolumn{3}{|c|}{ - Sulfasalazine } \\
\hline Yes & $1.23 \pm 0.11$ & \multirow[t]{2}{*}{0.631} \\
\hline No & $1.21 \pm 0.13$ & \\
\hline \multicolumn{3}{|c|}{ - TNF inhibitor } \\
\hline Yes & $1.22 \pm 0.13$ & \multirow[t]{2}{*}{0.774} \\
\hline No & $1.21 \pm 0.09$ & \\
\hline
\end{tabular}

NSAIDs non-steroidal anti-inflammatory drugs, TNF tumor necrosis factor

the high-resolution peripheral quantitative computed tomography revealed a lower lumbar TBS in AS patients in comparison to the controls $[10,25]$.

The results of the current study revealed that in patients with AS, TBS of the lumbar spine was directly correlated with BMI and BMD at the neck of femur and total hip while correlated inversely with the BASMI, mSASS, ESR, and CRP. In the Caparbo et al. study, AS patients with normal TBS were significantly younger in age, had significantly lower BMI, and higher BASMI than those with low TBS [25]. Technical issue can explain the inverse relationship between the TBS and BMI in the Caparbo et al. study, because TBS is negatively correlated with soft tissue thickness as it brings noise to the image [29].

Kang et al. compared TBS and BMD between patients with axSpA and controls and found that patients with axSpA appeared to have low bone quality in the lumbar spine in comparison with matched controls when assessed by TBS. In patients with axSpA, however not in controls, ESR or CRP, markers of systemic inflammation, had inverse correlation with TBS. Furthermore, these markers and radiographic spinal progression scores were autonomously related to decreased TBS [26]. Such results are consistent with the findings of the present study. In patients with axSpA, the inverse correlation 
found between TBS and inflammatory markers proposes that TBS mirrors inflammation-related changes occurring in the trabecular bone of the lumbar spine. For this reason, TBS is better to evaluate bone quality in the spine, as it seems to be a superior indicator of the risk of osteoporosis and vertebral fracture in these patients.

Assumed from our findings, more emphasis could be placed on the importance of TBS in the assessment of bone quality, in particular in AS patients with normal or increased BMD. Another preference of the lumbar spine TBS is that it can be evaluated on a regular basis by the same scan obtained for measuring BMD of the lumbar spine, and thus can easily be involved into regular clinical practice.

\section{Conclusion}

TBS evaluation detected lower bone quality in the lumbar spine in patients with AS when compared with matched controls, while lumbar BMD failed to identify it. These findings encourage the use of TBS as a beneficial tool to recognize the risk of axial osteoporosis as early as possible in AS patients. Also, we recommend its use for regular follow-up of drug treatment for those patients.

\section{Abbreviations \\ AS: Ankylosing spondylitis; ASAS: The Assessment of SpondyloArthritis international Society; ASDAS: AS disease activity score; ASQoL: AS Quality of Life questionnaire; axSpA: Axial spondyloarthritis; BASDAI: Bath AS Disease Activity Index; BASFI: Bath AS Functional Index; BASMI: Bath AS Metrology Index; BMI: Body mass index; BMD: Bone mineral density; CRP: C-reactive protein; DMARDs: Disease Modifying Anti-Rheumatic Drugs; DXA: Dual energy X-ray absorptiometry; ESR: Erythrocyte sedimentation rate; IRB: Institutional Review Board; mSASS: Modified Stoke AS Spinal Score; NSAI Ds: Non-steroidal anti-inflammatory drugs; SD: Standard deviation; TBS: Trabecular bone score}

\section{Acknowledgements}

Not applicable

\section{Authors' contributions}

Study conception and design by YA, MA and SA. YA and SA were responsible for data acquisition, data analysis, statistical analysis, manuscript drafting, and. MA was responsible for performing all radiological investigations present in the study and data analysis and critically revising the manuscript for important intellectual content. All authors read and approved the final manuscript

\section{Funding}

No funding

\section{Availability of data and materials}

The datasets used and/or analyzed during the current study are available from the corresponding author on reasonable request.

\section{Ethics approval and consent to participate}

The research was approved by the Institutional Review Board (IRB)/Mansoura Faculty of Medicine/Mansoura University (R/20.05.839; approval date, 14 May 2020). The written consent was obtained from all participants and approved by IRB.

\section{Consent for publication}

Not applicable in this study as there are no personal details.

\section{Competing interests}

The authors declare that they have no competing interests.

\section{Author details}

${ }^{1}$ Physical Medicine, Rheumatology and Rehabilitation Department, Faculty of Medicine, Mansoura University, Mansoura, Egypt. ${ }^{2}$ Diagnostic Radiology Department, Faculty of Medicine, Mansoura University, Mansoura, Egypt.

Received: 17 June 2020 Accepted: 24 July 2020

Published online: 14 August 2020

\section{References}

1. Wang R, Ward MM (2018) Epidemiology of axial spondyloarthritis: an update. Curr Opin Rheumatol 30(2):137-143

2. Carter S, Lories RJ (2011) Osteoporosis: a paradox in ankylosing spondylitis. Curr Osteoporos Rep 9(3):112-115

3. El Maghraoui A (2004) Osteoporosis and ankylosing spondylitis. Joint Bone Spine 71(4):291-295

4. Carter S, Braem K, Lories RJ (2012) The role of bone morphogenetic proteins in ankylosing spondylitis. Ther Adv Musculoskelet Dis 4(4):293-299

5. El Maghraoui A, Borderie D, Cherruau B, Edouard R, Dougados M, Roux C (1999) Osteoporosis, body composition, and bone turnover in ankylosing spondylitis. J Rheumatol 26:2205-2209

6. Van Der Weijden MAC, Claushuis TAM, Nazari T, Lems WF, Dijkmans BAC, Van Der Horst-Bruinsma IE (2012) High prevalence of low bone mineral density in patients within 10 years of onset of ankylosing spondylitis: A systematic review. Clin Rheumatol.: 1529-35.

7. Magrey M, Khan MA (2010) Osteoporosis in ankylosing spondylitis. Curr Rheumatol Rep 12(5):332-336

8. Gilgil E, Kaçar C, Tuncer T, Bütün B (2005) The association of syndesmophytes with vertebral bone mineral density in patients with ankylosing spondylitis. J Rheumatol 32(2):292-294

9. Magrey MN, Lewis S, Asim Khan M (2016) Utility of DXA scanning and risk factors for osteoporosis in ankylosing spondylitis-A prospective study. Semin Arthritis Rheum 46(1):88-94

10. Klingberg E, Lorentzon M, Göthlin J, Mellström D, Geijer M, Ohlsson C, et al (2013) Bone microarchitecture in ankylosing spondylitis and the association with bone mineral density, fractures, and syndesmophytes. Arthritis Res Ther; 15(6): R179.

11. Nigil Haroon N, Szabo E, Raboud JM, Mcdonald-Blumer H, Fung L, Josse RG et al (2015) Alterations of bone mineral density, bone microarchitecture and strength in patients with ankylosing spondylitis: a cross-sectional study using high-resolution peripheral quantitative computerized tomography and finite element analysis. Arthritis Res Ther 17:377

12. Silva BC, Leslie WD, Resch H, Lamy O, Lesnyak O, Binkley N et al (2014) Trabecular bone score: a noninvasive analytical method based upon the DXA image. J Bone Miner Res 29(3):518-530

13. Kolta S, Briot K, Fechtenbaum J, Paternotte S, Armbrecht G, Felsenberg D et al (2014) TBS result is not affected by lumbar spine osteoarthritis. Osteoporos Int 25(6):1759-1764

14. Padlina I, Gonzalez-Rodriguez E, Hans D, Metzger M, Stoll D, AubryRozier B et al (2017) The lumbar spine age-related degenerative disease influences the BMD not the TBS: the Osteolaus cohort. Osteoporos Int 28(3):909-915

15. Rudwaleit M, van der Heijde D, Landewe R et al (2009) The development of Assessment of SpondyloArthritis international Society classification criteria for axial spondyloarthritis (part II): validation and final selection. Ann Rheum Dis 68(6):777-783

16. Van der Heijde D, Lie E, Kvien TK, Sieper J, Van den Bosch F, Listing J et al (2009) ASDAS, a highly discriminatory ASAS-endorsed disease activity score inpatients with ankylosing spondylitis. Ann Rheum Dis 68(12):1811-1818

17. Machado $P$, van der Heijde D (2011) How to measure disease activity in axial spondyloarthritis. Curr Opin Rheumatol 23(4):339-345

18. Jenkinson TR, Mallorie PA, Whitelock HC (1994) Defining spinal mobility in ankylosing spondylitis (AS): the Bath AS Metrology Index. J Rheumatol 21(9): 1694-1698

19. Calin A, Garrett S, Whitelock H, Kennedy LG, O'Hea J, Mallorie P et al (1994) A new approach to defining functional ability in ankylosing spondylitis: the development of the Bath Ankylosing Spondylitis Functional Index. J Rheumatol 21(12):2281-2285 
20. Doward LC, Spoorenberg A, Cook SA, Whalley D, Helliwell P, Kay L et al (2003) Development of the ASQoL: a quality of life instrument specific to ankylosing spondylitis. Ann Rheum Dis 62(1):20-26

21. Creemers MC, Franssen MJ, van't Hof MA, Gribnau FW, van de Putte LB, van Riel PL (2005) Assessment of outcome in ankylosing spondylitis: an extended radiographic scoring system. Ann Rheum Dis 64(1):127-129

22. McCloskey EV, Oden A, Harvey NC, Leslie WD, Hans D, Johansson H et al (2016) A meta-analysis of trabecular bone score in fracture risk prediction and its relationship to FRAX. J Bone Miner Res 31(5):940-948

23. Liu YL, Hsu JT, Shih TY, Luzhbin D, Tu CY, Wu J (2018) Quantification of volumetric bone mineral density of proximal femurs using a twocompartment model and computed tomography images. Biomed Res Int 2018:6284269

24. Wildberger L, Boyadzhieva V, Hans D, Stoilov N, Rashkov R, Aubry-RozierB (2017) Impact of lumbar syndesmophyte on bone health as assessed by bone density (BMD) and bone texture (TBS) in men with axial spondyloarthritis. Joint Bone Spine; 84(4): 463-466

25. Caparbo VF, Furlam P, Saad CGS, Alvarenga JC, Aubry-Rozier B, Hans D et al (2019) Assessing bone impairment in ankylosing spondylitis (AS) using the trabecular bone score (TBS) and high-resolution peripheral quantitative computed tomography (HR-pQCT). Bone. 122:8-13

26. Kang KY, Goo HY, Park SH, Hong YS (2018) Trabecular bone score as an assessment tool to identify the risk of osteoporosis in axial spondyloarthritis: a case-control study. Rheumatology (Oxford) 57(3):462-469

27. Paolino S, Botticella G, Casabella A, Fasciolo D, Sulli A, Cutolo M (2015) Evaluations of bone microarchitectural status of the lumbar spine in ankylosing spondylitis patients by trabecular bone score assessment. Ann Rheum Dis 74(2):508-509

28. Geusens P, Chapurlat R, Schett G, Ghasem-Zadeh A, Seeman E, de Jong J et al (2014) High-resolution in vivo imaging of bone and joints: a window to microarchitecture. Nat Rev Rheumatol 10(5):304-313

29. Kolta S, Etcheto A, Fechtenbaum J, Feydy A, Roux C, Briot K (2019) Measurement of trabecular bone score of the spine by low-dose imaging system (EOS ): a feasibility study. J Clin Densitom 22(2):243-248

\section{Publisher's Note}

Springer Nature remains neutral with regard to jurisdictional claims in published maps and institutional affiliations.

\section{Submit your manuscript to a SpringerOpen ${ }^{\circ}$ journal and benefit from:}

- Convenient online submission

- Rigorous peer review

- Open access: articles freely available online

- High visibility within the field

- Retaining the copyright to your article

Submit your next manuscript at $\boldsymbol{\nabla}$ springeropen.com 